\title{
Noise and Health in Vulnerable Groups: A Case Study of a Diagnostic Clinic for Autistic Children in Mohammedpur, Dhaka
}

\author{
Anika Tabassum* and Sheikh Muhammad Najmul Imam \\ Department of Architecture, Bangladesh University of Engineering and Technology, Dhaka, Bangladesh
}

\begin{abstract}
A comfortable acoustical environment is imperative for the safety, well-being and recovery of patients receiving treatment in any type of healthcare service. Unfortunately, lack of satisfactory acoustical performance in most healthcare buildings worldwide has led to unfavorable prevailing conditions such as extremely noisy environment, irritation, disturbance, deterioration of a patient's health, and increase in likelihood of being readmitted into hospitals. This paper presents a case study on a diagnostic clinic targeted for autistic individuals in Mohammedpur, Dhaka as an attempt to investigate prevailing conditions of acoustical performance in healthcare facilities of Dhaka city. Questionnaire survey on users, instrumental survey on background noise levels and observations were conducted to obtain quantitative and qualitative data on acoustical performance. Instrumental survey results indicate that noise levels inside the specified clinic ranged from 59.5 to $76.5 \mathrm{dBA}$ - exceeding the allowable limits of local and international standards. Questionnaire survey results also signify users' dissatisfaction with existing noise conditions and thus a poor acoustical environment. This study is expected to develop awareness on current unacceptable acoustical conditions of healthcare facilities and provide tentative propositions to commence effective initiatives for developing design criteria for healthcare buildings in general, and those for autistic group in particular.
\end{abstract}

Keywords: healthcare environment; autism; noise levels; assessment of patients

\section{Introduction}

In the design of traditional healthcare facilities, extensive emphasis has been usually placed upon effectiveness of various functions and activities, as well as billings and costs, sterilization of equipment, medical treatments, facilities and technology (Dutro, 2007). However, less amount of significance has been presented on acoustical design considerations (Bliefnick and Ryherd, 2019, Jiang and Verderber, 2017). Acoustical design considerations are currently absent in the design, planning and construction of most healthcare buildings worldwide, including Bangladesh (Editorial Board, 2020, Staff Correspondent, 2020, Editorial, 2020, Rahman et al., 2016, Chiran, 2019).

Among the many prevailing factors currently assessed during design phases in healthcare facilities, the most significant one lies in controlling background noise levels (Xyrichis et al., 2018, Vishniac and Ryherd, 2019). Noise can be defined as the unwanted sound causing disturbance to nearby individuals (Ermann, 2015). Proper acoustical environment is extremely vital in any building, including healthcare buildings. There has been an increase in initiatives taken to spread awareness on the issues of background noise level control in healthcare facilities and this has become exponentially evident in recent times. Background noise levels in most hospitals, healthcare buildings and clinics in North America, Europe and Asia have still been surpassing the allowable upper limits of $30-40 \mathrm{dBA}$ set up by the World Health Organization (WHO) (Clarke, 2011, WHO, 2020, Xyrichis et al., 2018). In Bangladesh, average noise levels in healthcare buildings exceeds $45 \mathrm{dBA}$, which is the allowable limit set by Environmental Conservation Act - 1995 (ECA '95) and Environmental Conservation Rules 1997 (ECR '97) (Haq et al., 2012). Some examples of these cases are given below (Haq et al., 2012, Rahman et al., 2016, Hoque et al., 2013, Alam et al., 2006). 
- Bangabandhu Sheikh Mujib Medical University (Dhaka) - 75 dBA

- Bangladesh Institute of Research and Rehabilitation in Diabetes, Endocrine and Metabolic Disorders (BIRDEM) General Hospital (Dhaka) - 85.6 dBA

- Dhaka Medical College Hospital (Dhaka) - 61 to 72 dBA

- Green Life Diagnostic Hospital (Mymensingh) - 103 dBA

- Khanam Memorial (Tangail): 70 to 94 dBA

- City Poly Clinic (Sylhet): $70 \mathrm{dBA}$

Inside any healthcare facilities, sound may generate from different devices present in its surroundings such as alarms, beepers, machines, rolling carts, furniture movement, Heating Ventilation and Air Conditioning (HVAC) systems as well as from animate objects such as human conversation (Clarke, 2011). When the sound generating from these sources exceed the tolerable level, it may cause irritation amongst the occupants and at times instigate physiological and psychological injury to patients - depending on their prevailing conditions as for example age, hearing ability, medication intake etc. (Hammerson, Niemann and Hoebel, 2016, Bliefnick and Ryherd, 2019). It can contribute to poor sleep quality, which can delay healing rates of patients (Loupa, 2020). Excess levels of noise can also cause difficulty in staff communications and in some circumstances, noise distractions can be associated to increased errors in medical judgement (Bedlam and Dietz, 2016, Zaman, Dodds and Xiang, 2019).

Perhaps the most vulnerable group in this scenario are users who suffer from various types of neurological disorders such as Autism Spectrum Disorder (ASD). ASD causes problems in social communication and interaction, and it affects the way the brain analyses information to process and execute day to day activities (Gomes, Pedroso and Wagner, 2008, Hobson, 2019). Children and adolescents who have ASD tend to demonstrate strong behavioral over-reactivity to sound. Approximately $90 \%$ of individuals with autism have some form of abnormalities in sensory-perception; the most common one being hypersensitivity to sound (Chang et. al, 2012, Kanakri et al., 2017, Mamashli, 2017, Kuiper, Verhoeven and Geurts, 2019, Park et al., 2017). In a study conducted on a group of children with ASD in California, it was reported that $40 \%$ of all autistic children and adolescents had exhibited hypersensitivity to background noise levels exceeding $70 \mathrm{dBA}$ (Gomes, Pedroso and Wagner, 2008). Consequently, they tend to show an increase in abnormal behavioral problems (e.g. head banging, screaming, biting, tantrums, aggression), as most of them cannot communicate effectively about their hypersensitivity issues to other people (Kanakri et al., 2017, Kuiper, Verhoeven and Geurts, 2019, Steensel and Heeman, 2017, Smith and Matson, 2010, Boonen et al., 2014, Mazurek and Sohl, 2016, Hill et al., 2014, Matson, Gonzalez and Rivet, 2008). The cause of this hypersensitivity is still unknown to experts in the medical field (Gladysz, Krzywdzinska and Hozyasz, 2018, Caminha and Lampreia, 2012).

Individuals who have ASD require special attention and care in their daily lives and activities. At the same time, ensuring proper acoustical environment of diagnostic facilities such as clinics is of vital importance in order to improve staff efficiency, increase accuracy of assessment of the conditions of ASD individuals brought to these diagnostic clinics, minimize disturbances from inside and outside, ensure speech privacy, and enhance patient comfort and dignity (Bedlam and Dietz, 2016, Clarke, 2011, Roy, 2017, Anand, Walker and Saxena, 2019).

\section{Problem statement}

In recent times, acoustical performance has not been considered as an important criterion during the planning, design and construction phases of healthcare facilities. There has been a prevailing lack of awareness on the negative impacts of excessive noise levels on the physiological and psychological well-being of caregivers, patients and staff members of a clinic building. Additionally, there has been a lack of awareness on ASD in the 
context of Dhaka city, including awareness on the adverse impacts of prolonged exposure to excessive background noise levels on these individuals. This has resulted in an unsatisfactory level of acoustical performance (in terms of excessive background noise levels) in diagnostic clinics for autistic individuals located in Dhaka city. Moreover, rules and regulations for achieving acoustical comfort for clinics catering to individuals suffering from any type of disability has been nonexistent in the planning, design and construction codes and guidelines of Dhaka city.

\section{Objectives of the research}

This study investigates the conditions of acoustical performance inside diagnostic clinics for autistic individuals in Dhaka city. It includes objectives which focused on evaluating whether prevailing background noise conditions were satisfactory or not, assessing existing levels of deviations from local and international standards and recommendations, and investigating probable reasons behind any levels of deviation found. The research was limited by time, access and confidentiality constraints, as well as small sample size, and therefore low statistical power.

\section{Methodology of the research}

The acoustical performance evaluation work involved performing a subjective qualitative questionnaire survey on the clinic physician, staff members and outside visitors, and analyzing their responses to identify situations of high and low satisfaction; initial observations with the help of check-list for familiarization purposes and to identify areas having acoustical performance issues; choosing measurement locations and test conditions of objective instrumental survey; performing and analyzing acoustical measurements obtained from objective instrumental survey; and reflecting on the tentative propositions stemming from final results.

A checklist was prepared prior to conducting the field investigations, and was used to observe and document various features and attributes of the clinic such as interior dimensions, layout of furniture, materials of exterior finishing, interior finishing details, typical operating hours with corresponding peak hours, and total number of users occupying the studied floor. Sound Transmission Class (STC) ratings of the construction and design materials inside the clinic were also recorded.

Acoustical performance of the clinic was evaluated by measuring prevailing background noise levels. Background noise levels were measured in the main clinic space and its adjacent areas, using a Lutron SL 4023 model digital data logger type sound level meter. At each position, measurements of noise levels were recorded at four time periods (ranging from 10.30 AM to 5.00 PM), over a period of 15 days in April 2019, and the average for each time period calculated. Measurements were taken in the central position in the floor plan of each selected space. Table 1 shows the permissible upper limits of background noise levels and STC ratings of building and interior finishing materials according to acoustical standards for healthcare buildings and clinics, which were used for assessing levels of deviation in acoustical measurements in this research.

Table 1 Acoustical measurement parameters and acceptable criteria used in the study. (Source: Government of the People's Republic of Bangladesh, 2015)

\begin{tabular}{lll}
\hline $\begin{array}{l}\text { National acoustical standards for clinic and } \\
\text { healthcare buildings }\end{array}$ & $\begin{array}{l}\text { Parameters investigated in this } \\
\text { research }\end{array}$ & Permissible limit \\
\hline Noise Pollution Control Rules 2016 & Background Noise Level & Less than 45 dBA \\
\hline Bangladesh National Building Code (BNBC) 2015 & Background Noise Level & $\begin{array}{l}\text { Less than 33 to } \\
\text { 4B dBA }\end{array}$ \\
\hline Bangladesh National Building Code (BNBC) 2015 & Sound Transmission Class rating & At least 50 dBA \\
\hline
\end{tabular}




\section{Field investigation}

The study involved a four storied privately owned building located in Shamoli, Mohammedpur, Dhaka; all the floors had been rented by a non-profitable, non-government, voluntary organization for autistic individuals. It provided various services to children and adolescents with ASD such as education and training, outreach program, awareness program, vocational training, seminars and workshops for parents and teachers, and early intervention program. One of the most significant services they provided was early screening, diagnosis and assessment of individuals who may have ASD. The building had been occupied by this organization since 2004 . The building was located in a residential area, with no other building typologies standing within $400 \mathrm{~m}$ of its radius. The selected building had a $6.1 \mathrm{~m}$ wide road on the front (southern side), a 5 storied residence towards the south, a 4 storied high residence $3.05 \mathrm{~m}$ away from the north edge, a 4 storied high residence $2.44 \mathrm{~m}$ from the western edge and a 5 storied high residence $2.44 \mathrm{~m}$ from the eastern edge.

The assessment clinic (7.90 sq m.) was located on the first floor (250.83 sq m. area), which followed a typical floor plan of the building and thus was repeated in the other floors as well (Figure 1). Other functions present in this floor were classrooms for ASD students aged 3 to 10 years, Principal's room, waiting area for clinic (also uses as play zone by ASD students), administration section and computer room for ASD students. The clinic had an attached verandah (2.40 sq $\mathrm{m}$.) towards the south overlooking the main street (Figure 2), waiting area or play zone (24.5 sq m.) towards the north (Figure 2), and classrooms at the west and east (approximately $12.07 \mathrm{sq} \mathrm{m}$.) (Figure 2). The clinic's main physician, her assistants and some of the teachers overlooked the clinic's activities, including assessment of the patient's condition and private discussions with the parents or guardians. Approximately 45 occupants were present in the first floor at any given time.

Sundays and Mondays were chosen for instrumental survey as according to the physician, these days typically inclined on being the busiest times of the week for the clinic. Background noise levels were measured at three locations - the clinic, the waiting area and the verandah. The time periods chosen for measuring background noise levels were 10.30 AM, 12.00 PM, 3.30 PM and 5.00 PM. 

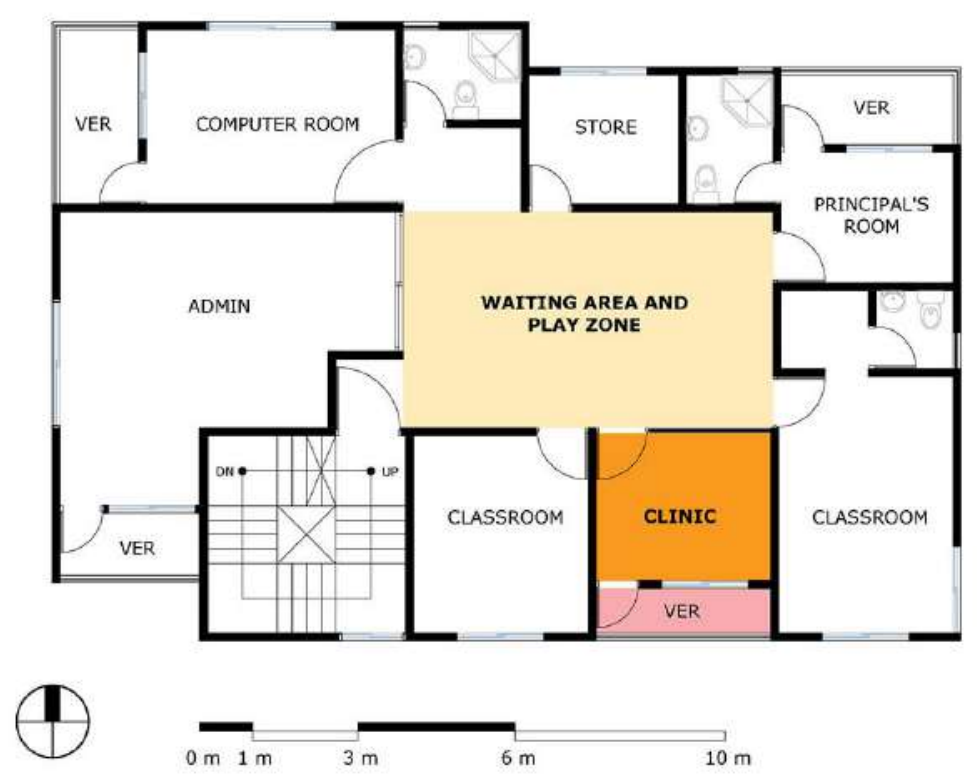

Figure 1 First floor plan of the selected case study, where the clinic was located. (Source: Author)
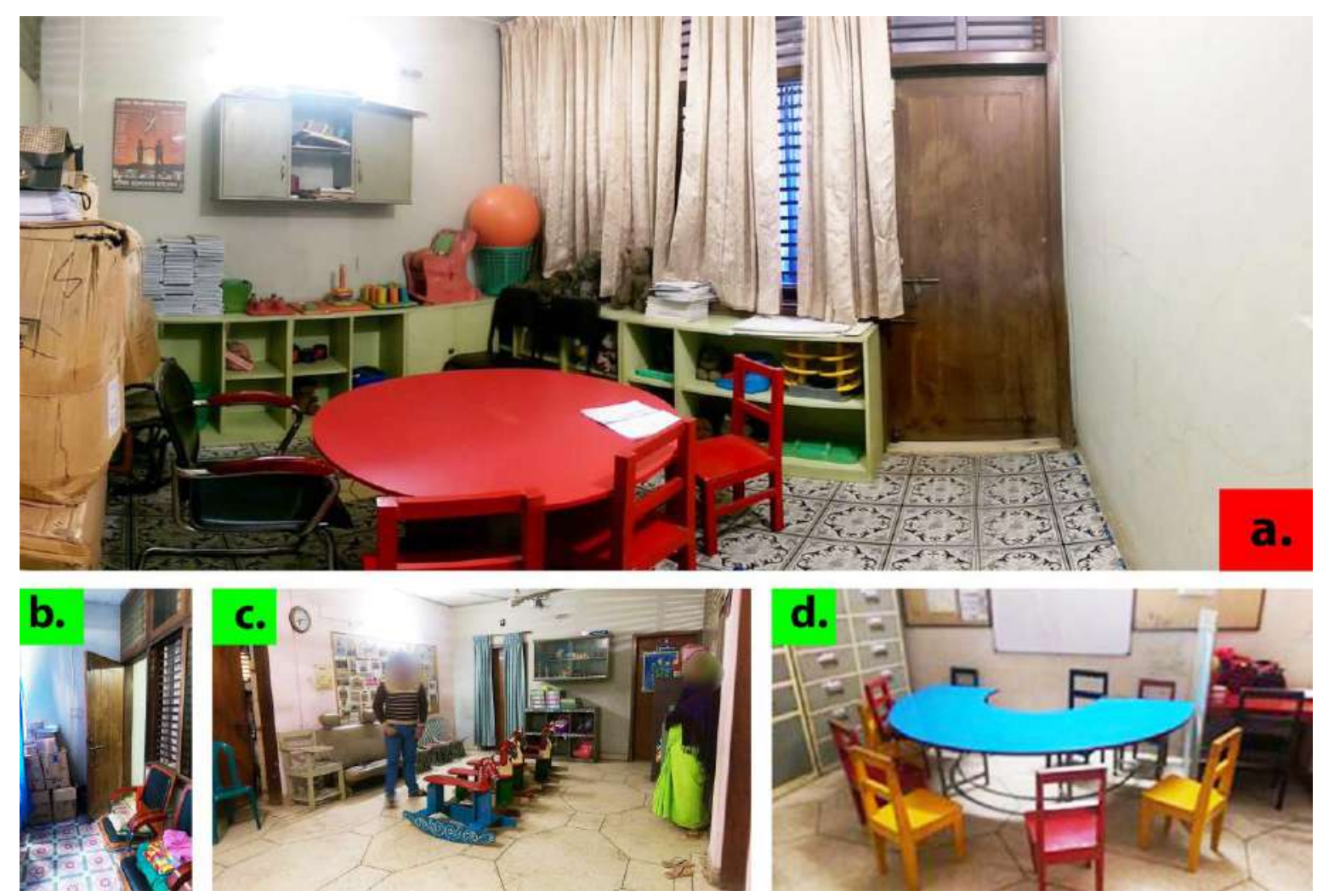

Figure 2 Interior planning and layout of a. Main diagnostic clinic $b$. Verandah attached with the clinic $c$. Waiting area outside the clinic, also used as play zone by ASD students d. Typical classrooms located adjacent to the clinic. (Source: Author) 


\section{Subjective qualitative survey analysis}

The subjective qualitative questionnaire survey asked the physician, staff members, teachers and outside visitors of the clinic (a total of 40 participants) about their general satisfaction with the environment of the clinic and their contentment with its acoustical performance. A semi-structured questionnaire having 8 to 14 questions were distributed among the survey participants. The main aim of the survey was to assess the level of disturbance generally felt by users due to existing background noise levels inside the clinic. Most of the ratings of each evaluation aspect were done on a five-point scale - for example, 'not at all, slightly, moderately, strongly, extremely' or 'never, rarely, sometimes, often, all the time'. Physician and staff members were also asked further questions regarding the time periods when the clinic was perceived as being 'noisy', impacts of existing noise levels on job performance and methods used to tackle excess noise levels.

Figure 3 shows the results of subjective qualitative survey conducted among the selected participants. In general, most of the occupants were not satisfied with the overall acoustical performance of the clinic. Almost $90 \%$ of the participants responded that the clinic 'often' got noisy during operating hours. $85 \%$ also remarked that they 'often' faced annoyance and disturbance on a daily basis due to existing noise levels in the clinic. Additionally, $75 \%$ of the respondents felt that most noise issues inside the clinic area were experienced during 12.00 PM and 5.00 PM. It was observed that these stated time periods coincided with the closing times of the morning shift and afternoon shift classes, during which increased levels of background noise were generated in the waiting area due to movement and voices of the teachers and students, who were exiting from the adjacent classrooms. This was also reflected in the questionnaire survey results, where $95 \%$ of the participants stated that most of the background noise levels were caused by tantrums, yelling and movement of students, and activities of users present in the waiting area. On the contrary, none of the participants felt that noise from the street next to the clinic's verandah contributed in increasing the noise levels inside the clinic. They remarked that even though noise levels inside classrooms were generally high, this noise was typically not heard by occupants inside the clinic space. Around $67 \%$ participants thought that relocating the clinic to a quieter zone - further away from the noisy waiting area and adjacent classrooms - would have been the ideal solution in order to alleviate excess background noise levels. However, most of the respondents were not aware of the negative impacts of prolonged exposure of noise on their own physiological and psychological health, with less than $30 \%$ users acknowledging with the adverse effects of noise on one's well-being. 


\section{Does the clinic ever get noisy?}

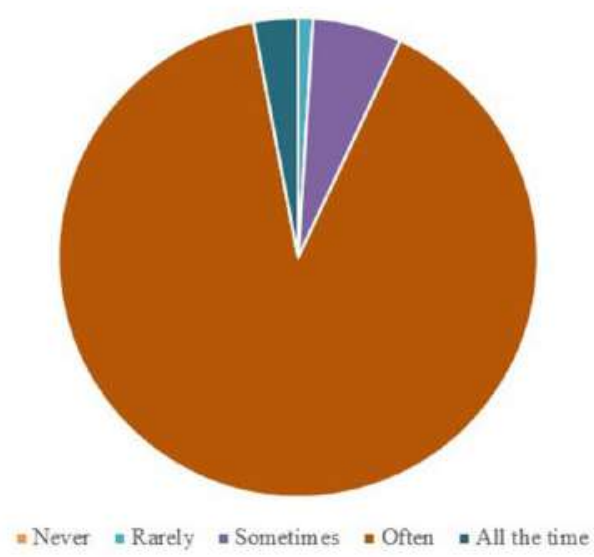

\section{Do you ever face annoyance due to noises in} clinic?

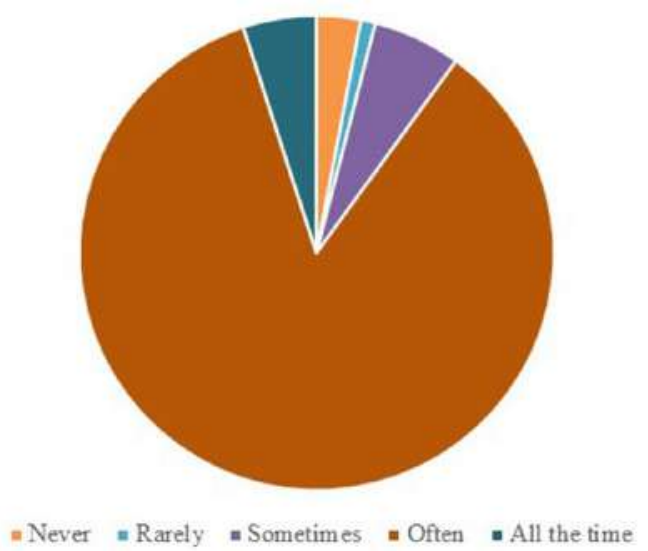

Do you feel noise levels are harming your health?

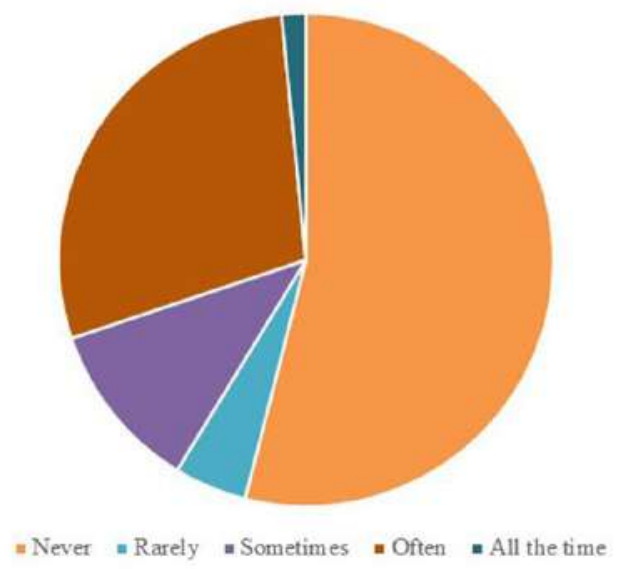

Figure 3 Summary of main results of subjective qualitative survey conducted on the physician, staff members, teachers and visitors. (Source: Author)

A number of additional questions were also asked to the physician and selected staff members and teachers on the first floor in order to gain insight on how existing background noise levels were affecting their daily job performance. Similar remarks were observed during this additional questionnaire survey, as illustrated in Figure 4. More than $65 \%$ of these participants expressed their dissatisfaction with the existing high levels of background noise prevailing in the clinic space, and how it 'extremely' had a negative influence on their work efficiency and productivity. $75 \%$ felt that they were 'often' annoyed by the noise levels presiding in the clinic while they were working. In addition, almost $80 \%$ respondents informed that they 'often' faced interruptions in their daily tasks due to existing high levels of background noise. Most of these participants generally tackled prevailing excessive noise conditions by lodging a complaint to their coworkers and manager, or by working additional hours. Additionally, most of these participants acknowledged the positive correlation between excessive background levels and behavior issues in ASD individuals - with almost $80 \%$ of the participants stating that existing noise levels inside the clinic 'often' triggered autistic students and patients to respond aggressively by exhibiting abnormal behavior. As a result, it often disrupted activities inside the clinic, waiting area and classroom. Participants felt that high levels of background noise might have caused "abnormal 
behavioral problems", "heightened feelings of pain", "annoyance" and "hearing loss" in autistic individuals. This indicates that parents, guardians, staff members and teachers were generally aware about the negative impacts of excessive noise levels on autistic individuals. This may be contributed to their increased levels of adequate understanding about the difficulties autistic individuals face in their daily lives, as because they have either resided or worked alongside with them for many years.

\section{Do noise levels affect job performance?}

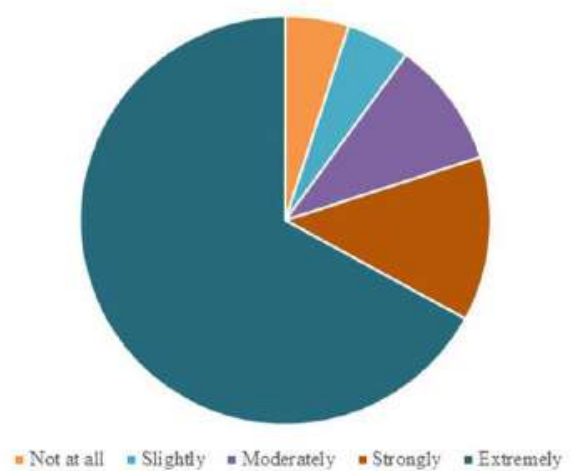

\section{Do you get annoyed by noise levels?}

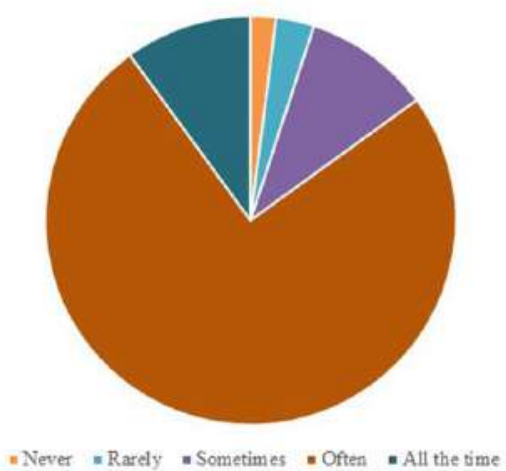

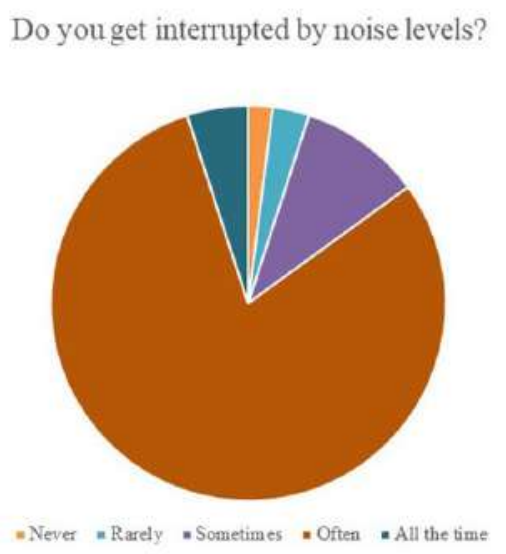

Do noise levels trigger behavior issues in ASD individuals?

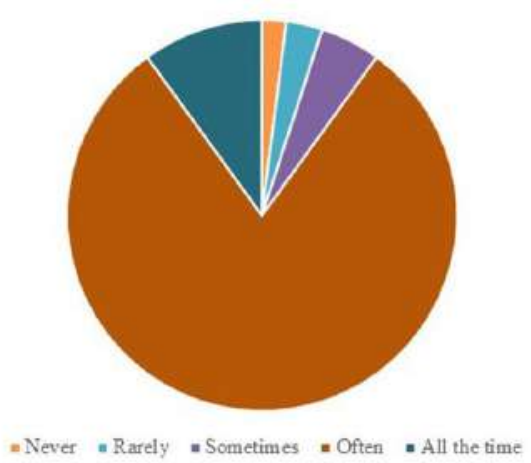

Figure 4 Summary of main results of subjective qualitative survey conducted on the physician, staff members and teachers. (Source: Author)

In addition, $90 \%$ of the participants stated that no measures in terms of proper acoustical design and planning were ever taken to control noise levels in the clinic, even after complaints were places to the management committee. In fact, $95 \%$ of the participants stated that the main physician often had to go outside the clinic and reprimand the occupants in the waiting area to maintain low voices during conversations. However, they never rebuked the autistic individuals, as they felt "they are not making noises or behaving aggressively on purpose". This suggests that even if staff members, teachers and visitors maintained decorum and conversed silently, the unpredictable behavior issues of autistic individuals would still persist. Hence, appropriate acoustical design and planning schemes regarding these different zones is of more significance, rather than monitoring the actions of autistic individuals. 


\section{Initial observations}

By means of initial observation and photographic data, various features and attributes of the clinic with respect to acoustical performance were evaluated. Some initial observations were deduced about the characteristics of the building components of the clinic.

- The clinic was located adjacent to two classrooms. As a result, it was more susceptible to excessive noise levels due to continuous activities of teachers and students whenever they came out of these active areas.

- $\quad$ BNBC (2015) states that a dedicated waiting area and lobby space should be provided for any clinic or consultation space. No lobby space solely dedicated for the clinic was present. The waiting area for the studied clinic was also being used by ASD students to play during recess period, and other users also frequently occupied this area. As a result, high noise levels were prevalent in this space during the school operating hours.

- $\quad$ BNBC (2015) also states that the STC ratings of walls and floor of a consultation room should be at least $50 \mathrm{dBA}$. However, STC rating of the double layer of $18 \mathrm{~mm}$ plywood on wooden frames (making the total thickness of $76 \mathrm{~mm}$ ) (located at the north of the clinic room) and $127 \mathrm{~mm}$ thick brick wall (located at the west, east and south) separately was around $45 \mathrm{dBA}$, which is less than the minimum recommended limit.

- The walls and ceiling of the clinic area had been kept bare, and had not been treated with any specialized materials for noise control purpose. The floor was covered with a very thin $0.1 \mathrm{~mm}$ PVC mat, which does not contribute in enhancing noise absorption.

- Wooden louvers present in the partition wall at the north had not been lined with acoustic louvers.

- Windows installed in the southern wall of the clinic area were single glazed. However, for restricting entry of excessive level of indoor noise, double glazed windows are recommended for being installed in peripheral walls by standards.

\section{Objective instrumental survey analysis}

Table 2 summarizes the main results of the acoustical measurements.

Table 2 Summary of main results of acoustical measurements in the studied clinic. (Source: Author)

\begin{tabular}{lccc}
\hline Quantity & Location & $\begin{array}{c}\text { Allowable upper limit of } \\
\text { indoor background noise } \\
\text { level (BNBC 2015) }\end{array}$ & $\begin{array}{c}\text { Average value } \\
\text { calculated (over 15 } \\
\text { days period) }\end{array}$ \\
\hline Background noise level & Clinic & 33 to $48 \mathrm{dBA}$ & $66.4 \mathrm{dBA}$ \\
\cline { 2 - 4 } & Waiting area & 33 to $48 \mathrm{dBA}$ & $72.7 \mathrm{dBA}$ \\
\cline { 2 - 4 } & Verandah & 33 to $48 \mathrm{dBA}$ & $45.5 \mathrm{dBA}$ \\
\hline
\end{tabular}

Inside the clinic, the average background noise level over the 15-days period and at all times was found to be 66.4 dBA, which exceeds the allowable upper limit of indoor background noise levels according to guidelines formulated by BNBC (2015). Similarly, average background noise level for the waiting area was 72.7 dBA, which also exceeds the allowable upper limit. Average background noise levels inside the verandah was found to be the lowest among the three studied spaces, and was within the allowable upper limit range of indoor noise levels, having an acceptable value of $45.5 \mathrm{dBA}$.

Figure 5 shows the average indoor background noise levels calculated at each of the four selected time periods. 


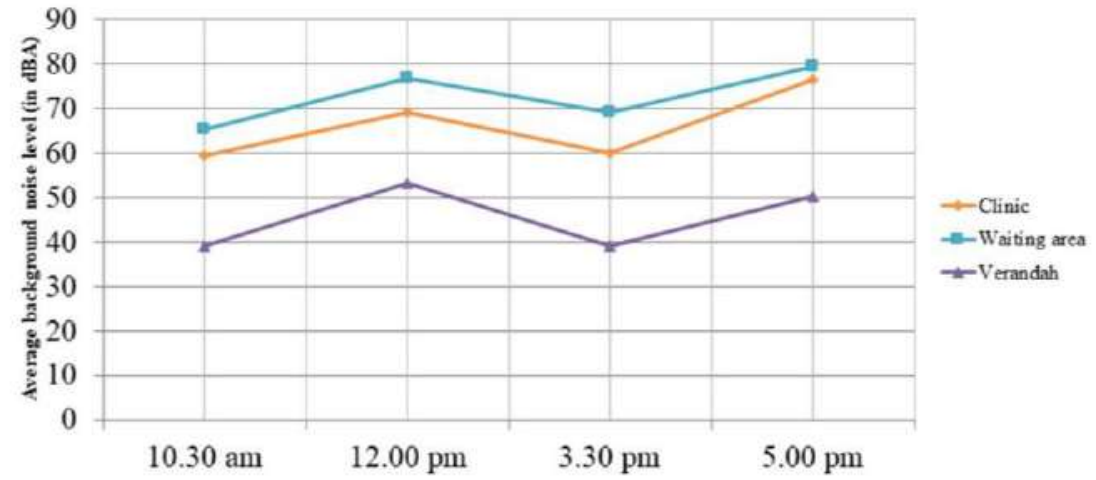

Figure 5 Average background noise levels obtained for each time period in the clinic, waiting area and verandah. (Source: Author)

From the data displayed in Figure 5, it can be seen that average background noise levels exceeded the permissible limit at all time periods inside the clinic and waiting area, and was the highest during $12.00 \mathrm{PM}$ and 5.00 PM for the clinic. This is comparable to the results found from the subjective qualitative survey analysis, where most of the participants remarked that they frequently experienced high levels of noise in the clinic during 12.00 PM and 5.00 PM. Average background noise levels inside the clinic were above permissible range, regardless of any occupants being present or not. Additionally, among all the studied spaces, average noise levels were found to be the highest in the waiting area, especially when it was occupied by staff members, students, teachers and visitors, and whenever any ASD individual was having a tantrum in that area. Average noise levels inside the verandah exceeded the permissible limit during 12.00 PM and 5.00 PM, but the overall average noise level was still lower than the maximum permissible limit.

From observations and field survey, some of the possible sources of sound which contributed to high background noise levels inside the clinic during the 15-days study period are as follows:

- Movement of teachers, staff members, visitors and students in the waiting area (footsteps, chattering)

- Yelling or tantrum of students in the waiting area

- Structure borne noise inside the clinic and waiting area (furniture movement, slamming of doors)

- Conversation of teachers, staff members and visitors in the waiting area

\section{Discussion and conclusion}

The acoustical environment of any healthcare building, including clinics and consultation areas, is often considered to be the least satisfactory aspect by its users. Appropriate acoustical measures regarding design and planning of diagnostic clinics are extremely inadequate. Occupants are dissatisfied with excessive indoor background noise levels, and consider that the prevailing acoustical environment does not enhance their ability to work. The results of the objective instrumental survey measurements help explain the subjective qualitative survey results:

- Background noise levels: Excessive noise levels often tend to be annoying, stressful, tiring and may hinder verbal communication as well as work efficiency. Existing background noise levels in the studied diagnostic clinic in Dhaka city were found to be unsatisfactory and exceeds the permissible limits mentioned in local and international standards. Deviations between average background noise levels of the clinic from the standards and 
recommendations is significantly high, as much as $38.3 \%$ higher. Additionally, dissatisfaction with the acoustical environment inside the clinic often resulted from noise sources in the adjacent waiting area. Noise levels due to user activity can be significantly high when the acoustical conditions are poor (e.g. when there is excess levels of reverberation). Furthermore, design aspects and planning guidelines stated by BNBC for healthcare buildings is missing in the clinic's final design and layout. The findings of the questionnaire survey further reinforce this observation.

- Productivity: The acoustical environment of a clinic augments a user's ability to conduct any task efficiently when it is comfortable, absent of any disruptions and supports easy verbal communication (i.e. speech is easy to comprehend using a comfortable voice level). Excessive background noise levels can make a clinic area uncomfortable to occupants, and it can also contribute to inadequate levels of speech intelligibility in the space. Insufficient noise isolation between the clinic and waiting area (caused by inadequate partition design, insufficient STC ratings of partition materials or the inadequate attenuation of propagating sounds due to insufficient sound absorption measures) can result in excessive background noise levels in waiting area being heard inside the clinic, causing disturbances and reduced concentration in tasks.

It was noted that a general lack of awareness between prolonged exposure of high background noise levels and the physiological and psychological health prevails among most individuals. The most vulnerable group in this scenario are individuals with neurological disorders such as ASD.

Many of the acoustical performance issues which have been identified in the studied clinic area are also observed in other types of healthcare buildings, as because inadequate attention is often paid to their acoustical design and consideration. The results of this particular research confirm that improving acoustical environment in any healthcare buildings, including diagnostic clinics, primarily necessitates appropriate acoustical design that is, the application in design of existing knowledge, with contribution from an acoustical specialist included into the design team from the start of the planning and design process. This knowledge relates to site selection and building orientation, the planning and layout of internal spaces, the building layout and internal partitions, to the appropriate dimensioning of spaces, separating and zoning of noisy and quiet spaces, and the amount and location of suitable acoustically treated materials. For a satisfactory acoustical performance, the guidance provided by the acoustical design expert must be abided by, and the necessary funding must be made available for it to be implemented. In addition, Post Occupancy Evaluation (POE) surveys should be carried out on the building occupants to assess the acoustical performance of the space after occupancy, and to identify and mitigate any prevailing problems. Proper etiquette and decorum in terms of activity noises and speech level intensities should be maintained among occupants. Awareness on the relationship between excess levels of background noise and impaired physiological and psychological health should be increased.

Employing proper acoustical design and planning schemes inside diagnostic clinics can greatly enhance the overall sound environment for both patients as well as employees, staff members, visitors and caregivers. It is of significant importance to vulnerable groups such as autistic individuals, who show more hypersensitivity to auditory stimuli than the general population. This study provides baseline data for conducting further research to determine appropriate architectural design solutions for acoustical environment of diagnostic clinics and other healthcare facilities. Failure to resolve these issues may limit the development of a satisfactory healthcare acoustical environment and compromise with the well-being of occupants, particularly autistic groups.

\section{Acknowledgements}

The authors would like to thank the Department of Architecture, Bangladesh University of Engineering and Technology (BUET) for their support in this work. They also gratefully acknowledge the support of Autism 
Welfare Foundation (AWF) and Bangladesh Medical College Hospital (BMCH), Dhaka, Bangladesh for their support and guidance.

\section{References}

ALAM, J. B. et al., 2006, Study on Traffic Noise Level of Sylhet by Multiple Regression Analysis associated with Health Hazards. Iran. J. Environ. Health. Sci. Eng., 3(2), 71-78.

ANAND, S. A., WALKER, P., and SAXENA, N., 2019. Compromising Speech Privacy under Continuous Masking in Personal Spaces. Proceedings of $17^{\text {th }}$ International Conference on Privacy, Security and Trust (PST), Fredericton, NB, Canada, August, pp. 1-10.

BELDAM, M. B. and DIETZ, B., 2016. The Impact of Sound and Room Acoustics in Healthcare Facilities: A Room Acoustic Intervention Study in A Dementia Clinic in Munich. Proceedings of INTER-NOISE and NOISE-CON Congress and Conference: Inter-Noise2016, Hamburg, Germany, August, pp. 4661-4669.

BLIEFNICK, J. M., and RYHERD, E. E., 2019, Evaluating hospital soundscapes to improve patient experience. The Journal of the Acoustical Society of America, 145, 1117.

BOONEN, H. et al., 2014, Behavior problems among school-aged children with autism spectrum disorder: Associations with children's communication difficulties and parenting behaviors. Research in Autism Spectrum Disorder, 8(6), 716-725.

CAMINHA, R. C., and LAMPREIA, C., 2012, Findings on sensory deficits in autism: implications for understanding the disorder. Psychology \& Neuroscience, 5(2), 231-237.

CHANG, M. C. et al., 2012, Autonomic and behavioral responses of children with autism to auditory stimuli. American Journal of Occupational Therapy, 66, 567-576.

CHIRAN, M., 2019, A deafening cacophony: Unabated honking on roads a menace for hospital patients. The Daily Star, 26 August.

CLARKE, S., 2011. Acoustic design approach for hospitals. Proceedings of ACOUSTICS 2011, Gold Coast, Australia, November, pp. 1-6.

DUTRO, A. R., 2007, Light Image Therapy in the Health Care Environment. Working paper, East Tennessee State University.

EDITORIAL BOARD, 2017, Dangerous sound pollution. The Independent, 8 November.

EDITORIAL, 2020, Noise pollution warrants early govt attention. New Age, 12 January.

EDITORIAL BOARD, 2020, Grappling with noise pollution. The Financial Express, 14 January.

ERMANN, M. A., 2015, Architecture Acoustics Illustrated $2^{\text {nd }}$ Ed. (New Jersey, U.S.A.: John Wiley \& Sons).

GOMES, E., PEDROSO, F. S., and WAGNER, M. B., 2008, Auditory hypersensitivity in the autistic spectrum disorder. Pró-Fon oRevista de Atualização Científica, 20(4), 279-284.

GOVERNMENT OF THE PEOPLE'S REPUBLIC OF BANGLADESH, Housing and Building Research Institute, 2015, Bangladesh National Building Code 2015, Final Draft.

GLADYSZ, D., KRZYWDZINSKA, A., and HOZYASZ, K. K., 2018, Immune Abnormalities in Autism Spectrum Disorder - Could They Hold Promise for Causative Treatment? Molecular Neurobiology, 55, 63876435.

HAMMERSEN, F., NIEMANN, H., and HOEBEL, J., 2016, Environmental Noise Annoyance and Mental Health in Adults: Findings from the Cross-Sectional German Health Update (GEDA) Study 2012. International Journal of Environmental Research and Public Health, 13(10), 954.

HAQ, M. A. et al., 2012, Status of Noise Pollution in Mixed Areas of Dhaka City: a GIS Approach. Journal of Environmental Science and Natural Resources, 5(1), 9-17.

HILL, A. P. et al., 2014, Aggressive behavior problems in children with autism spectrum disorders: Prevalence and correlates in a large clinical sample. Research in Autism Spectrum Disorders, 8(9), 1121-1133. 
HOBSON, R. P., 2019, Autism and the development of the mind: Essays in developmental psychology (New York, U.S.A.: Routledge).

HOQUE, M. M. et al., 2013, Level of noise pollution at different locations in Tangail municipal area, Bangladesh. Bangladesh Journal of Scientific Research, 26(1), 29-36.

JIANG, S., and VERDERBER, S., 2017, On the Planning and Design of Hospital Circulation Zones: A Review of the Evidence-Based Literature. Health Environments Research \& Design Journal, 10(2), 124-146.

KANAKRI, S. M. et al., 2017, Noise and autism spectrum disorder in children: An exploratory survey. Research in Developmental Disabilities, 63, 85-94.

KUIPER, M. W. M., VERHOEVEN, E. W. M., and GEURTS, H. M., 2019, Stop Making Noise! Auditory Sensitivity in Adults with an Autism Spectrum Disorder Diagnosis: Physiological Habituation and Subjective Detention Thresholds. Journal of Autism and Developmental Disorders, 49, 2116-2128.

LOUPA, G., 2020, Influence of Noise on Patient Recovery. Current Pollution Reports, 6, 1-7.

MAMASHLI, F. et al., 2017, Auditory processing in noise is associated with patterns of disrupted functional connectivity in autism spectrum disorder. Autism Research, 10(4), 631-647.

MAZUREK, M. O., and SOHL, K., 2016, Sleep and Behavioral Problems in Children with Autism Spectrum Disorder. Journal of Autism and Developmental Disorders, 46, 1906-1915.

PARK, W. J. et al., 2017, High internal noise and poor external noise filtering characterize perception in autism spectrum disorder. Scientific Reports, 7, 1-12.

RAHMAN, M. M. et al., 2016, Effect of Noise Pollution on Patients in Hospitals and Health Clinics of Mymensingh Sadar Upazila. International Journal of Innovation and Applied Studies, 18(1), 97-106.

ROY, K. P., 2017, Possible path for speech privacy design and performance approaches. The Journal of the Acoustical Society of America, 142, 2626.

SMITH, K. R. M., and MATSON, J. L., 2010, Behavior problems: Differences among intellectually disabled adults with co-morbid autism spectrum disorders and epilepsy. Research in Developmental Disabilities, 31(5), 1062-1069.

STAFF CORRESPONDENT, 2020, Noise pollution serious health issue for Dhaka city residents. Prothom Alo, 11 January.

STEENSEL, F. J. A., and HEEMAN, E. J., 2017, Anxiety Levels in Children with Autism Spectrum Disorder: A Meta-Analysis. Journal of Child and Family Studies, 26, 1753-1767.

VISHNIAC, I. B., and RYHERD, E., 2019, Hospital Soundscapes: Characterization, Impacts, and Interventions. Acoustics Today, 15(3), 11-18.

WHO, 2020, Guidelines for Community Noise - World Health Organization, Date of access: 24/03/2020? https://www.who.int/docstore/peh/noise/Comnoise-4.pdf

XYRICHIS, et al., 2018, Noise pollution in hospitals. BMJ 2018, 363, 4808.

ZAMAN, K., DODDS, P., and XIANG, N., 2019, Impacts of noise on staff cognitive performance in a hospital emergency department. The Journal of the Acoustical Society of America, 145, 1658. 